\title{
Homogeneous Photoredox System for Hydrogen Production by Solar Energy
}

\author{
M. Gohn and N. Getoff \\ Institut für Theoretische Chemie und Strahlenchemie der Universität Wien
}

Z. Naturforsch. 34a, 1135-1139 (1979); received July 23, 1979

In a redox system consisting of $5 \times 10^{-5} \mathrm{~mol} \mathrm{dm}^{-3} \mathrm{Ru}(\mathrm{bpy})_{3}{ }^{2+}$ complex, $4 \times 10^{-3} \mathrm{~mol} \mathrm{dm}^{-3}$ methylviologen and $5 \times 10^{-3} \mathrm{~mol} \mathrm{dm}^{-3}$ EDTA in aqueous solutions $(\mathrm{pH}=3$ to 8.5 ) without catalyst, hydrogen is formed under illumination with light $\lambda>360 \mathrm{~nm}$. The highest yield was established in the pH-range between 4 and 5. The degradation of the components by prolonged use was studied spectroscopically. For comparison hydrogen evolution was also studied replacing EDTA by TEA or $\mathrm{SCN}^{-}$, respectively, in the above mentioned system.

\section{Introduction}

Various attempts have been made in the last years in order to develope suitable redox systems for photochemical utilization of solar energy. Thereby special attention has been paid to rutheniumbipyridil-complexes as a suitable mediator for photon energy in such devices [1-4]. Using monolayer films of $\mathrm{Ru}(\mathrm{bpy})_{3}{ }^{2+}$ derivatives immersed in water, hydrogen evolution under illumination was reported [5]. Subsequently, however, these observations could not be reproduced [6-9]. Recently, it has been demonstrated that with rutheniumtrisbipyridil $\left(\mathrm{Ru}(\mathrm{bpy})_{3}{ }^{2+}\right)$, applied as a photosensitizer in combination with a suitable electron acceptor (e.g. methylviologen, $\mathrm{MV}^{2+}[10,11]$ or a rhodium-bipyridil complex $[12,13])$ and an electron donor (e.g. triethanolamine, TEA $[11,12]$ or EDTA [10]) in aqueous solutions, hydrogen is produced under illumination with light of $\lambda>400 \mathrm{~nm}$. A catalyst, such as $\mathrm{PtO}_{2}$ (Adam's catalyst) [11], colloidal Platinum [10] or in situ generated Pt [12] was always necessary to promote the reaction of $\mathrm{H}_{\mathrm{aq}}^{+}$with the reduced electron acceptor leading to hydrogen formation. The yields were strongly $\mathrm{pH}$ dependent and the maximum value of $3.6 \times 10^{-4}$ $\mathrm{H}_{2}$ mol dm${ }^{-3} \mathrm{~h}^{-1}$ was obtained at $\mathrm{pH}=7$, applying a $450 \mathrm{~W}$ Xe-lamp and a cut-off filter for $\lambda<400 \mathrm{~nm}$ [11]. Other authors found $2.3 \times 10^{-3} \mathrm{H}_{2} \mathrm{~mol} \mathrm{dm}^{-3} \mathrm{~h}^{-1}$ at $\mathrm{pH}=5$ (light $\lambda>400 \mathrm{~nm}$ ) $[10]$ and $4.5 \times 10^{-3}$ $\mathrm{H}_{2}$ mol dm $\mathrm{dm}^{-3} \mathrm{~h}^{-1}$ at $\mathrm{pH}=7.5$ (150 W halogen lamp [13]). In all cases a degradation of the substrates in

Reprint requests to Prof. Dr. N. Getoff, Institut für Theor. Chemie und Strahlenchemie, Universität Wien, Währingerstrasse 38, A-1090 Wien.

0340-4811/ 79 / 0900-1135 \$01.00/0.

Please order a reprint rather than making your own copy. the solution was observed. Thereby turnover numbers were determined to be 10 for $\mathrm{MV}^{2+}$ and 100 for $R u(b p y){ }_{3}{ }^{2+}[10]$ in one case and 150 for the Rh-complex and 2300 for $\mathrm{Ru}(\mathrm{bpy})_{3}{ }^{2+}$ in a second case [13]. Those for the electron donor (TEA or EDTA) were near unity.

The reduced form of methylviologen, namely $\mathrm{MV}^{+}[14,15]$, is of special interest, as its redox potential $\left(E^{0}=-0.44 \mathrm{~V}[16]\right.$ or $E^{0}=-0.466 \mathrm{~V}$ [17]) is negative enough to reduce water to hydrogen. On the other hand, according to the previously presented reaction mechanism, a degradation of the electron donor occurs [10-13]. This fact, however, is of basic importance regarding a practical use of such systems. Hence, experiments with a system consisting of $\mathrm{Ru}(\mathrm{bpy})_{3}{ }^{2+}, \mathrm{MV}^{2+}$ and EDTA without catalyst were designed in order to examine the stability of the substrates and the efficiency of the hydrogen production. In this case the blue coloured radical cation, $\mathbf{M V}^{+}$, should also become electronically excited under the applied steady-state conditions and its reactivity will be essentially enhanced. In addition to this $\mathrm{PtO}_{2}$ was added as a catalyst to the same system to check its influence. Further it was attempted to replaced the amine, acting as an electron donor, by a regenerable inorganic substrate.

\section{Experimental}

$\mathrm{Ru}(\mathrm{bpy})_{3}{ }^{2+}$ was synthesized from $\mathrm{RuCl}_{3}$ and 2,2'-Dipyridil [18]. 2,2'-Dipyridil (Koch-Light, Coinbrook, England), methylviologen (BDH Chemicals Ltd., Poole, England) and all other chemicals (Merck, Darmstadt, FRG) were of analytical grade and used without further purification. The solutions 
were prepared with 4 times distilled water. A double wall irradiation vessel $(d=2,8 \mathrm{~cm}, l=6 \mathrm{~cm}$, containing $30 \mathrm{ml}$ solution) was connected with a thermostat. The solutions of: $5 \times 10^{-5} \mathrm{~mol} \mathrm{dm}^{-3}$ $\mathrm{Ru}(\mathrm{bpy})_{3}{ }^{2+}, \quad 4 \times 10^{-3} \mathrm{~mol} \mathrm{dm}^{-3} \mathrm{MV}^{2+}, \quad 4 \times 10^{-3}$ $\mathrm{mol} \mathrm{dm}-3 \mathrm{EDTA}$, or $5 \times 10^{-2} \mathrm{~mol} \mathrm{dm}^{-3} \mathrm{SCN}^{-}$or $5 \times 10^{-2} \mathrm{~mol} \mathrm{dm}^{-3}$ TEA were saturated for about $1 \mathrm{~h}$ with high purity argon (Messer Griesheim, Vienna). The $\mathrm{pH}$ values were adjusted with $\mathrm{HClO}_{4}$ or $\mathrm{NaOH}$. The irradiations were performed with a $450 \mathrm{~W}$ Xe-lamp (Oriel), equipped with a $10 \mathrm{~cm}$ IR-water filter and a cut-off glass filter for $\lambda<360 \mathrm{~nm}$.

The produced hydrogen was collected by means of a vacuum line and determined by gas chromatography (Fractovap, $116 \mathrm{E}$, molecular sieve $5 \AA$, Perkin Elmer).

\section{Results}

\subsection{Photochemical Behaviour of Ru(bpy $)_{3}{ }^{2+}$ in Aqueous Solution}

It is supposed that unlike many metal complexes, $\mathrm{Ru}(\mathrm{bpy})_{3}{ }^{2+}$ does not readily undergo the photochemical loss of ligands [4]. In order to check its stability, absorption spectra of $5 \times 10^{-3} \mathrm{~mol} \mathrm{dm}^{-3}$ $\mathrm{Ru}(\mathrm{bpy})_{3}{ }^{2+}$ were measured in aqueous solutions at $\mathrm{pH}=6.5$ prior to and after illumination for up to 6 hours. The change of the optical density $\left(\mathrm{OD} \cdot \mathrm{cm}^{-1}\right)$ for several irradiation periods is presented in Figure 1.

\subsection{The Ru-complex $/ T E A / M V^{2+}$ System (with Catalyst)}

The photochemical formation of hydrogen by illuminating the homogeneous aqueous system consisting of $\mathrm{Ru}(\mathrm{bpy})_{3}{ }^{2+}, \mathrm{MV}^{2+}$, and TEA [11] was reinvestigated for comparison. This was necessary because the photochemical results in general strongly depend upon irradiation geometry, light intensity and other factors. A solution of $5 \times 10^{-5}$ $\mathrm{mol} \mathrm{dm}{ }^{-3} \mathrm{Ru}(\mathrm{bpy})_{3}{ }^{2+}, 4 \times 10^{-3} \mathrm{~mol} \mathrm{dm}^{-3} \mathrm{MV}^{2+}$, and $5 \times 10^{-2} \mathrm{~mol} \mathrm{dm}^{-3}$ TEA in the presence of $10-20 \mathrm{mg} \mathrm{PtO}_{2}(\mathrm{pH}=6.7)$ was illuminated under stirring for various periods. The amount of hydrogen evolved for the first $2 \mathrm{~h}$ of irradiation was less than observed by other authors [11]. This discrepancy is due to the above mentioned factors. After prolonged irradiation the hydrogen yields decrease substantially. Mean values for various irradiation periods are given in Table 1, series Nr. 1.

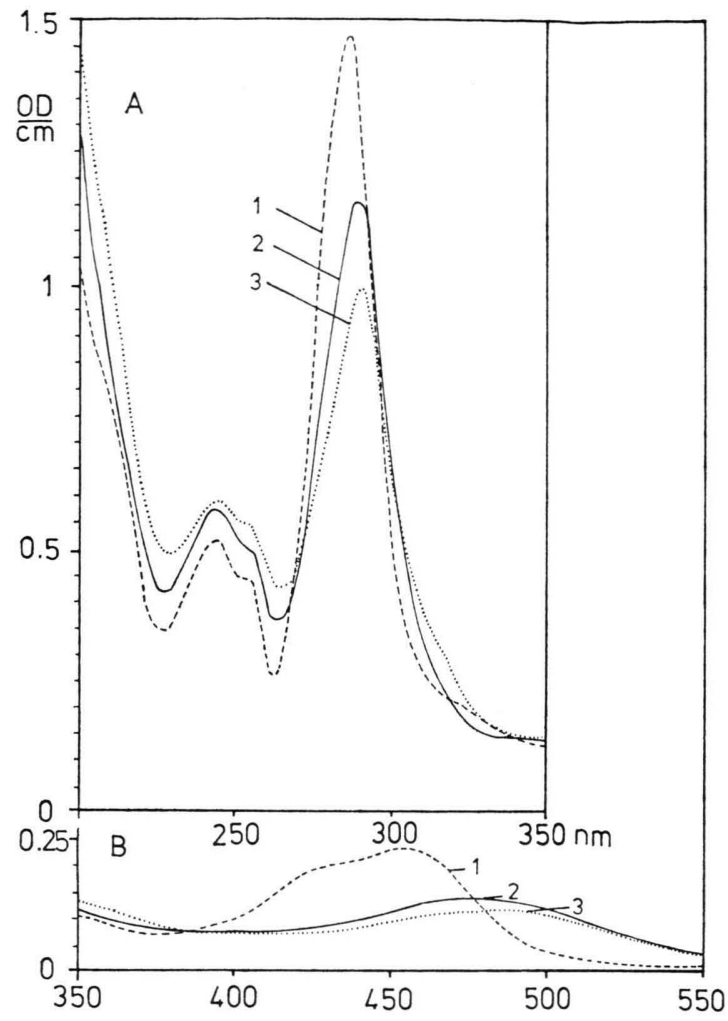

Fig. 1. Absorption spectra $5 \times 10^{-5} \mathrm{~mol} \mathrm{dm}^{-3} \mathrm{Ru}(\mathrm{bpy})_{3}{ }^{2+}$ complex before and after illumination $(\lambda>360 \mathrm{~nm})$ in aqueous solutions at $\mathrm{pH}=6.5(A=200$ to $350 \mathrm{~nm}, B=350$ to $550 \mathrm{~nm})$ : non-irradiated (1), irradiation time $2 \mathrm{~h} \mathrm{(2)}$ and $6 \mathrm{~h}(3)$.

Table 1. Hydrogen evolution by illuminating $(\lambda>360 \mathrm{~nm})$ photoredoxsystems containing $\mathrm{Ru}(\mathrm{bpy})_{3}{ }^{2+}$ in aqueous solutions, $\mathrm{pH}=6.7$.

\begin{tabular}{|c|c|c|c|c|}
\hline \multirow[t]{2}{*}{ Nr. } & \multirow[t]{2}{*}{ System } & \multicolumn{3}{|c|}{$\begin{array}{l}\times 10^{-5} \mathrm{~mol} \mathrm{dm}^{-3} \mathrm{H}_{2} \\
\text { obtained by irrad. times of: }\end{array}$} \\
\hline & & $2 \mathrm{~h}$ & $4 \mathrm{~h}$ & $6 \mathrm{~h}$ \\
\hline 1 & $\begin{array}{l}5 \cdot 10^{-5} \mathrm{~m} \mathrm{Ru}(\mathrm{bpy})_{3}{ }^{2+} \\
4 \cdot 10^{-3} \mathrm{~m} \mathrm{MV} \mathrm{MV}^{+} \\
5 \cdot 10^{-2} \mathrm{~m} \mathrm{TEA} \\
\text { with } \mathrm{PtO}_{2}\end{array}$ & 8 & 9.7 & 9.8 \\
\hline 2 & $\begin{array}{l}5 \cdot 10^{-5} \mathrm{~m} \mathrm{Ru}(\mathrm{bpy})_{3}{ }^{2+} \\
4 \cdot 10^{-3} \mathrm{~m} \mathrm{MV} \mathrm{MV}^{+} \\
5 \cdot 10^{-2} \mathrm{~m} \text { TEA } \\
\text { (without catalyst) }\end{array}$ & 16 & 28 & 31.8 \\
\hline 3 & $\begin{array}{l}5 \cdot 10^{-5} \mathrm{~m} \mathrm{Ru}(\mathrm{bpy})_{3}{ }^{2+} \\
4 \cdot 10^{-3} \mathrm{~m} \mathrm{MV}^{2+} \\
5 \cdot 10^{-2} \mathrm{~m} \mathrm{SCN}^{-} \\
\text {(without catalyst) }\end{array}$ & 0.2 & - & - \\
\hline
\end{tabular}


Additionally, it was of practical interest to investigate the photochemical stability of the system under prolonged irradiation conditions. A strong change of the absorption spectra at 260 and $450 \mathrm{~nm}$ taken as a function of irradiation time indicated an essential degradation process.

\subsection{Ru-complex $/ T E A / M V^{2+}$ System without Catalyst}

In order to obtain some more information about the effect of the catalyst in this system, experiments in its absence were carried out under otherwise unchanged conditions. The obtained hydrogen yields are much higher and are presented as series Nr. 2 in Table 1. The absorption spectrum after illumination for $6 \mathrm{~h}$ showed only a decrease of the OD-values in the range of $400-470 \mathrm{~nm}$, due to the degradation of the Ru-complex.

\section{4. $\mathrm{SCN}^{-}$as an Inorganic Electron Donor}

An attempt was made to substitute the electron donor TEA or EDTA by $0.05 \mathrm{~mol} \mathrm{dm}^{-3} \mathrm{SCN}^{-}$. All other compounds as well as irradiation conditions were kept unchanged. No catalyst was used in this system. At an irradiation time of $45 \mathrm{~min}(\mathrm{pH}=6.5)$ a relative small hydrogen yield was found (Table 1, series Nr. 3). It might be mentioned that in this case only a slight change of the absorption spectrum was observed after irradiation.

\subsection{The Ru-complex $/ E D T A / M V^{2+}$ System (without Catalyst)}

In analogy to the previously described systems, solutions in which TEA was replaced by $4 \times 10^{-3}$ mol dm ${ }^{-3}$ EDTA were irradiated under the same conditions at $\mathrm{pH}=3$ to 8.5 . No catalyst was used in this case. The mean $\mathrm{H}_{2}$-yields of several measurements (irradiation time $\mathbf{4 5} \mathrm{min}$ ) are summarized in Table 2. The absorption spectra measured before and after various irradiation times are shown in Figure 2.

\subsection{The Ru-complex $/ E D T A \mid M V^{2+}$ System with Catalyst}

In this series of experiments, the influence of $\mathrm{PtO}_{2}$ (Adam's catalyst) on the hydrogen production and photochemical stability of the complex was investigated. The composition of the solutions and the concentration of the components were the same
Table 2. Photochemical formation of hydrogen as a function of $\mathrm{pH}$ at $25^{\circ} \mathrm{C}$. Aqueous solutions of:

$5 \times 10^{-5} \mathrm{~mol} \mathrm{dm}^{-3} \mathrm{Ru}(\mathrm{bpy})_{3}{ }^{2+}, 4 \times 10^{-3} \mathrm{~mol} \cdot \mathrm{dm}^{-3} \mathrm{MV}^{+}$ and $4 \times 10^{-3} \mathrm{~mol} \mathrm{dm}^{-3}$ EDTA.

\begin{tabular}{lll}
\hline $\mathrm{pH}$ & $\begin{array}{l}\mathrm{H}_{2} \text {-yield } \\
\times 10^{-4} \mathrm{~mol} \mathrm{dm}^{-3} \cdot \mathrm{h}^{-1}\end{array}$ \\
& & \\
3.0 & 2.6 & \\
3.7 & 2.7 & \\
4.0 & 4.1 & \\
4.7 & 6.6 & \\
5.0 & 3.9 & $* 10$ mg of $\mathrm{PtO}_{2}$ \\
6.0 & 1.9 & added before \\
7.0 & 1.3 & illumination. \\
8.5 & 0.5 & \\
$4.6 *$ & 11.0 & \\
\hline
\end{tabular}

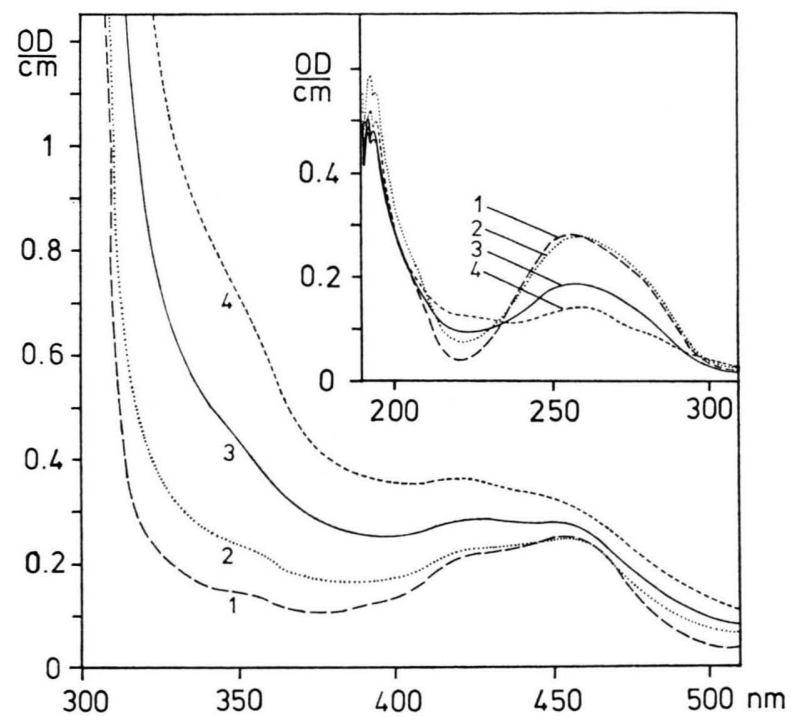

Fig. 2. Absorption spectra of the photoredoxsystem consisting of: $5 \times 10^{-5} \mathrm{~mol} \mathrm{dm}^{-3} \mathrm{Ru}(\mathrm{bpy})_{3}{ }^{2+}, \quad 4 \times 10^{-3} \mathrm{~mol}$ $\mathrm{dm}^{-3} \mathrm{MV}^{2+}$ and $4 \times 10^{-3} \mathrm{~mol} \mathrm{dm}^{-3}$ EDTA before and after various irradiation periods: non-irradiated (1), irra-

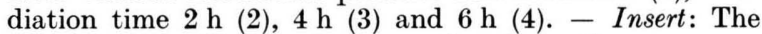
solution was diluted 250-times for absorption measurements below $300 \mathrm{~nm}$.

as above, but about $10 \mathrm{mg}$ of $\mathrm{PtO}_{2}$ catalyst were added to the solution. Irradiation conditions were not altered and the solution was thoroughly stirred during illumination. At the most favorable $\mathrm{pH}$ of 4.6, a hydrogen yield of $11 \times 10^{-4} \mathrm{~mol} \mathrm{dm}^{-3} \mathrm{~h}^{-1}$ was obtained for an illumination time of $45 \mathrm{~min}$. This yield is by a factor of 2 higher than in the absence of catalyst. Absorption spectra were measured before and after every $2 \mathrm{~h}$ of irradiation and are presented in Figure 3. 


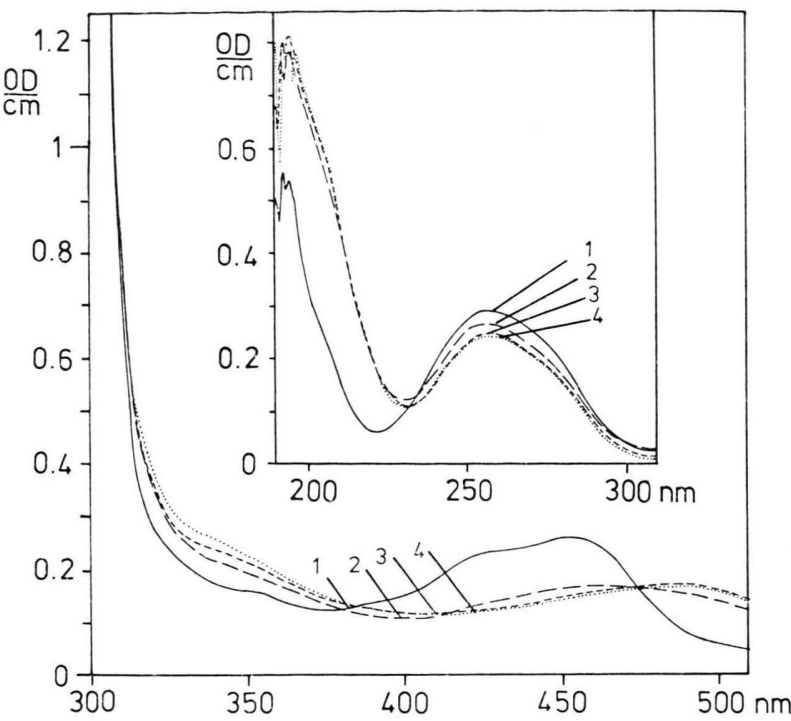

Fig. 3. Absorption spectra of the photoredoxsystem consisting of: $5 \times 10^{-5} \mathrm{~mol} \mathrm{dm}^{-3} \mathrm{Ru}(\mathrm{bpy}) 3^{2+}, 4 \times 10^{-3} \mathrm{~mol}$ $\mathrm{dm}^{-3} \mathrm{MV}^{2+}, 4 \times 10^{-3} \mathrm{~mol} \mathrm{dm}{ }^{-3}$ EDTA and $10 \mathrm{mg} \mathrm{PtO}_{2}$ (as catalyst) before and after various irradiation periods: non-irradiated (1), irradiation time $2 \mathrm{~h} \mathrm{(2),} 4 \mathrm{~h} \mathrm{(3)}$ and $6 \mathrm{~h}$ (4). - Insert: The solution was diluted 250-times for absorption measurements below $300 \mathrm{~nm}$.

\section{Discussion}

In contrast to previous results [4], it was established that the $\mathrm{Ru}(\mathrm{bpy})_{3}{ }^{2+}$ complex in aqueous solution $(\mathrm{pH}=6.5)$ is photochemically unstable (Figure 1). Obviously, a scission of ligands occurs under prolonged u.v.-irradiation. Based on the changes of the measured absorption spectra it can be concluded that the at present non-identified products can undergo slow reactions when in contact with oxygen.

By comparing the $\mathrm{H}_{2}$ yield using the previously investigated system $\left(\mathrm{Ru}(\mathrm{bpy})_{3}{ }^{2+} / \mathrm{MV}^{2+} / \mathrm{TEA}\right)$ in the presence of $\mathrm{PtO}_{2}$ (Adam's catalyst) [11] with that obtained in the absence of a catalyst, it is evident that the latter one is essentially higher. Thereby a strong change of the absorption spectra in the range of $400-470 \mathrm{~nm}$ was observed in both cases, indicating a degradation of the ruthenium complex. In the presence of the catalyst an additional decrease of the absorption at $\lambda \sim 260 \mathrm{~nm}$ occurs due to the photolysis of $\mathrm{MV}^{2+}$. The photochemical formation of hydrogen in this system can be explained by a previously postulated reaction mechanism [11], namely:

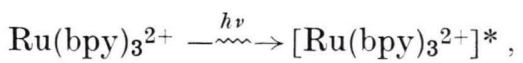

$$
\begin{aligned}
& {\left[\mathrm{Ru}(\mathrm{bpy})_{3}{ }^{2+}\right]^{*}+\mathrm{MV}^{2+} \rightarrow \mathrm{Ru}(\mathrm{bpy})_{3}{ }^{3+}+\mathrm{MV}^{+},} \\
& \mathrm{Ru}(\mathrm{bpy})_{3}{ }^{3+}+\mathrm{TEA} \rightarrow \mathrm{Ru}(\mathrm{bpy})_{3}{ }^{2+}+\mathrm{TEA}^{+}, \\
& \mathrm{MV}^{+}+\mathrm{H}_{\mathrm{aq}}^{+} \underset{\mathrm{PtO}_{2}}{\longrightarrow} \mathrm{MV}^{2+}+\mathrm{H} \\
& \mathrm{H}+\mathrm{H} \rightarrow \mathrm{H}_{2} \\
& k_{5}=1 \times 10^{10} \mathrm{dm}^{3} \mathrm{~mol}^{-1} \mathrm{~s}^{-1}
\end{aligned}
$$

The evolution of $\mathrm{H}$ atoms according to reactions (4) and their recombination (5) was found to proceed only by a depletion of the electron donor (TEA), which regenerates the sensitizer, $\mathrm{Ru}(\mathrm{bpy}) \mathbf{3}^{2+}$. The $\mathrm{H}$ atoms can naturally also attack each component of the system, which explains the observed degradation.

The $\mathrm{H}_{2}$ yield obtained in the absence of $\mathrm{PtO}_{2}$ is in contradiction to previous results $[10,11]$. In order to explain this fact, one can assume that by illuminating the system under steady-state conditions, the $\mathrm{MV}^{+}$radical cation, produced in surplus according to reaction (2), can be electronically excited $\left(\lambda_{\max }=395 \mathrm{~nm}\right.$ and $600 \mathrm{~nm}$ [20]). This is underlined by the fact that the solution turns blue shortly after beginning illumination. Subsequently, the electronically excited $\mathrm{MV}^{+}$is able to act as an electron donor by transfering an electron to $\mathrm{H}_{\mathrm{aq}}^{+}$:

$$
\begin{aligned}
& \mathrm{MV}^{+}-\stackrel{h v}{\rightarrow} \rightarrow\left[\mathrm{MV}^{+}\right]^{*}, \\
& {\left[\mathrm{MV}^{+}\right]^{*}+\mathrm{H}_{\mathrm{aq}}^{+} \rightarrow \mathrm{MV}^{2+}+\mathrm{H},}
\end{aligned}
$$

This process can occur as well with as without $\mathrm{PtO}_{2}$ catalyst. Further experiments are planned in order to explain the observed higher $\mathrm{H}_{2}$ value in the absence of a catalyst (Table 1).

The replacement of the electron donor by $\mathrm{SCN}^{-}$ gave no satisfactory results concerning the hydrogen yield, but only a small degradation of the system was observed. This indicates again that the higher $\mathrm{H}_{2}$ yield is accompanied by a strong destruction of the system. This confirms the formation of $\mathrm{H}$ atoms as intermediates and their reactivity with the substrates.

An interesting observation is the fact that $\mathrm{H}_{2}$ formation occurs not only by illuminating the Ru-complex in combination with $\mathrm{MV}^{2+}$ and EDTA in the presence of a Pt-catalyst [10], but also in its absence (Table 2). The formation of $\mathrm{H}_{2}$ in the second case is thereby very sensitive towards the acidity of the solution, showing a maximum yield at $\mathrm{pH}=4.7$. In this case EDTA acts as an electron 
donor for the oxidized Ru-complex, which is regenerated:

$\mathrm{Ru}(\text { bpy })_{3}{ }^{3+}+\mathrm{EDTA} \rightarrow \mathrm{Ru}(\mathrm{bpy})_{3}{ }^{2+}+\mathrm{EDTA}^{+}$. (8)

The formation of $\mathrm{H}_{2}$ is therefore due to the consecutive reactions (1), (2), (6), (7) and (8). The $\mathrm{pH}$ influence on the $\mathrm{H}_{2}$ yield using the analogous system (TEA as electron donor), but in the presence of the $\mathrm{PtO}_{2}$ catalyst, has already been explained [11]. At lower $\mathrm{pH}$ values very fast back reactions are postulated, corroborated by flash photolysis experiments, whereas at higher $\mathrm{pH}$ values the potential of the reduction of $\mathrm{H}_{\mathrm{aq}}^{+}$is shifted too far to the negative.

The changes of the absorption spectra caused by prolonged illumination of the Ru-complex/EDTA/ $\mathrm{MV}^{2+}$ system in the absence of a Pt-catalyst (Fig. 2) show an essential decrease of the $\mathrm{MV}^{2+}$ concentration $(\lambda \sim 260 \mathrm{~nm})$. Also an increase of the OD-values in the range of $300-400 \mathrm{~nm}$, probably due to photolytical products of $\mathrm{MV}^{2+}$, can be seen.

By adding $\mathrm{PtO}_{2}$ as a catalyst, the $\mathrm{H}_{2}$ yield doubled (Table 2). At the same time, a relatively lower degradation of the system was observed (Figure 3). This is explainable by the fact that in addition to reaction (7), reaction (4) takes place. Also, the recombination of $\mathrm{H}$ atoms is facilitated

[1] C. Creutz and N. Sutin, Proc. Nat. Acad. Sci. (USA), 72, 2858 (1975).

[2] C. T. Lin and N. Sutin, J. Phys. Chem. 80, 77 (1976).

[3] L. Moggi, p. 147 in "Solar Power and Fuels", ed. J. R. Bolton, Academic Press Inc., London 1977.

[4] N. Sutin, J. Photochem. 10, 19 (1979).

[5] G. Sprintschnik, H. W. Sprintschnik, P. P. Kirsch, and D. G. Whitten, J. Am. Chem. Soc. 98, 2337 (1976).

[6] G. Sprintschnik, H. W. Sprintschnik, P. P. Kirsch, and D. G. Whitten, J. Am. Chem. Soc. 99, 4947 (1977).

[7] G. L. Gaines, P. E. Behnken, and S. J. Valenty, J. Amer. Chem. Soc. 100, 6549 (1978).

[8] L. J. Yellowlees, R. G. Dickinson, C. S. Halliday, J. S. Bonham, and L. E. Lyons, Austr. J. Chem. 31, 431 (1978).

[9] N. Getoff, S. Solar, and M. Gohn, Naturwiss., in print.

[10] A. Moradpour, E. Amouyal, P. Keller, and H. Kagan, Nouveau J. Chim. 2, 547 (1978).

[11] K. Kalyanasundaram, J. Kiwi, and M. Grätzel, Helv. Chim. Acta 61, 2720 (1978). by the catalyst, thus preventing photolytic processes to some extent.

Summarizing the results obtained in the absence and presence of $\mathrm{PtO}_{2}$ as a catalyst in systems consisting of $\mathrm{Ru}(\mathrm{bpy})_{3}{ }^{2+}, \mathrm{MV}^{2+}$ and various electron donors (TEA, EDTA, $\mathrm{SCN}^{-}$), a production of hydrogen by sensitized photolysis of water can occur. In all cases, however, relatively strong degradation processes were observed, whereby the presence of catalysts suppresses the depletion of $\mathrm{MV}^{2+}$ up to a certain extent. On the other hand, the donor is always used up whilst hydrogen is formed. It is further established that $\mathbf{M} \dot{V}^{+}$in its electronically excited state can act as an electron donor towards $\mathrm{H}_{\mathrm{aq}}^{+}$. All these investigated systems a still far from a practical use as a device for the photochemical production of hydrogen by means of solar energy. Further search for a more suitable electron donor is necessary.

\section{Acknowledgement}

The authors like to express their thanks to the Fonds zur Förderung der wissenschaftlichen Forschung in Austria to the Ludwig-Boltzmann- Gesellschaft and to the Bundesministerium für Wissenschaft und Forschung for financial support.

[12] J. M. Lehn and J. P. Sauvage, Nouv. J. Chim. 1, 449 (1977).

[13] J. M. Lehn, J. F. Sauvage, and M. Kirch, Proc. 2nd. Int. Conf. Photochem. and Storage of Solar Energy late abstract, Cambridge 1978.

[14] J. R. Barnett, A.S. Hopkins, and A. Ledwith, J. Chem. Soc, Perkin Transact. II, 80 (1973).

[15] J. S. Bellin, R. Alexander, and R. D. Mahoney, Photochem. Photobiol. 17, 17 (1973).

[16] A. A. Krasnovskii and G. P. Brin, Dokl. Akad. Nauk SSSR, 16, 761 (1965).

[17] P. S. Rao and E. Hayon, J. Amer. Chem. Soc. 96, 1287 (1974).

[18] F. Burstale, J. Chem. Soc. 88, 173 (1966).

[19] M. Anbar, Farhataziz, and A. B. Ross, in: "Selected Specific Rates of Reactions of Transients from Water in Aqueous Solution", Nat. Bureau of Standards, Washington 1975.

[20] L. K. Patterson, R. D. Small, and J. C. Scaiano, Radiation Research 72, 218 (1977). 